\title{
chaper How the Voice of People with 1 Mental Health Problems, Families and the Voluntary Sector Changed the Landscape
}

\author{
Paul Farmer and Emily Blackshaw
}

\section{Introduction}

The years 1960-2010 mark a period of radical transformation for mental health in Britain. Like all social change, there were many actors in enabling the transformation to take place. This chapter focuses on the role of people with 'lived experience', their families and voluntary organisations in acting as catalysts, enablers and, in some cases, architects for change. The move from institutionalised care to care in the community was partly caused by, and in turn further strengthened, the voices of people with mental health problems. People with mental health problems and the friends and family who supported them, alongside other stakeholders and practitioners, formed, influenced and supported voluntary mental health organisations. The voluntary sector has since been a prominent and vocal force in mental health, supporting the rights of those with mental health problems and filling gaps in service provision, where community care has sometimes fallen short. Charities are in a unique position, sitting outside of statutory care and clinic-based spaces, allowing them to build reciprocal and trust-based relationships with the communities that they serve. The voluntary sector must continue to push for the voice of people with mental health problems to be front and centre of mental health service delivery and policymaking.

\section{Deinstitutionalisation: From Asylums to Care in the Community}

Going back as far as the Middle Ages, asylums were the main route of care for those with mental health problems. ${ }^{1}$ Asylums existed in an unregulated and inconsistent form across England in the eighteenth century, and it was not until the 1808 Country Asylums Act that 'Lunatic Asylums' were officially established for the poor and 'criminally insane'. These were further regulated with the 1845 Lunacy Act, which importantly changed the status of those it served from 'people' to 'patients'. ${ }^{2}$ Up until the establishment of the National Health Service (NHS), mental health services were subject to the 1890 Lunacy Act and the 1930 Mental Treatment Act, which set the terms for compulsory detention and treatment without certification. ${ }^{3}$ As one patient described their experience of being committed to Ticehurst Asylum in 1875, 'my liberty, and my very existence as an individual being, had been signed away behind my back'. ${ }^{4}$ People had no voice, they were 'out of sight and out of mind', locked away by a society which simply could not cope with mental ill health and consequentially stigmatised those who had mental health problems.

The First World War threw mental health problems into sharp relief. Approximately 80,000 British soldiers were treated for a range of war neuroses, generally known as 'shell 
shock', presenting with symptoms including tics, obsessive thoughts, fatigue and paralysis. ${ }^{5}$ Military medical professionals acknowledged the need to act on mental health, in order to preserve the morale and manpower of their troops, but this was far from the era of 'psychological modernity' that some argued enlightened post-war Britain. ${ }^{6}$ Psychotherapy remained the exception to the rule in terms of treatments for shell shock, which included medicinal remedies of iron, arsenic and Ovaltine as well as electrotherapy. ${ }^{7}$ Some doctors, such as W. H. R. Rivers (who famously treated the poet Siegfried Sassoon at Craiglockhart War Hospital) explored the psychological causes of shell shock, prescribing the 'talking cure' alongside creative activities. ${ }^{8}$ The collective trauma experienced by the British public during the First and Second World Wars may also have softened attitudes towards mental health and its treatment.

After the Second World War, society in Britain became increasingly concerned with social fairness, reflecting the wider political consensus for universal human rights (UN/ European declarations on human rights, later extended to the rights of disabled people), ${ }^{9}$ as well as marked changes in social order and structures, including the provision of universal health care. Two key changes started to emerge: the formation and gathering of voluntary organisations and the increasing opportunity for people with mental health problems to have a voice. These were not always easy encounters, with deep-seated stigma and resistance to the idea that 'the mad' could possibly have a view. Equally, family voices were often marginalised, caught between the clinician and the service user. In Alan Bennett's Untold Stories, he refers to his mother's history of depression and his grandfather's suicide and bemoans the lack of support available for families without unusual symptoms, 'mistake your wife for a hat and the doctor will never be away from your bedside'. ${ }^{10}$

\section{A Series of Scandals: Increased Service User Voice and Pressure from the Voluntary Sector}

In the 1950s and 1960s, several mental health hospital scandals broke, supported by accounts from people who were treated there, including Farleigh, South Ockendon and Normansfield (see also Chapter 7). The investigation into long-stay wards at Ely Hospital in Cardiff took place between 1967 and 1968 and is often cited as the start of 'an avalanche of scandal in mental health, ${ }^{11}$ although an earlier exposé Sans Everything: A Case to Answer foreshadowed many of the revelations. ${ }^{12}$ The Ely Committee reported evidence of rough and cruel treatment, inhumane and threatening behaviour towards patients and the pilfering of patients' belongings and food. ${ }^{13}$ Despite the best attempts of the government (the Ministry of Health sought to keep the Ely inquiry private, limiting a public appeal for witnesses and keeping the scope of the inquiry narrow), ${ }^{14}$ the allegations were supported and the story broke, shocking a concerned public and leading to increased governmental pressure. Other prominent scandals were featured heavily in the media, including the Shelton Hospital fire and overcrowding at Warwick Central Hospital, and calls for action were demanded by voluntary organisations. Mind (then known as the National Association for Mental Health, NAMH) condemned the handling of the inquiries in the Observer and worked in solidarity with service user groups such as the Patients' Association calling for more independent inquiries and support for the PostEly Working Party. ${ }^{15}$ Calls for changes to the 1959 Mental Health Act were also supported by the combined voices of people with mental health problems and pressure from groups such as NAMH. ${ }^{16}$ 
The voluntary sector remained at the forefront of the ongoing call for deinstitutionalisation. The then minister of health, Enoch Powell, made his remarkable 'Water Tower speech' at NAMH's annual conference in March 1961, where he called for the closure of large psychiatric hospitals, menacingly describing them as isolated, majestic, imperious, brooked over by the gigantic water-tower and chimney combined, rising unmistakeable and daunting out of the countryside'. 17 This was promptly followed by supportive legislation, including the 1962 A Hospital Plan for England and Wales, calling for the closure of all mental health beds by 1975, and the 1971 Hospital Services for the Mentally Ill White Paper, proposing the complete abolition of the hospital system for mental health care (see also Chapter 1).

The movement towards deinstitutionalisation in the 1960s and 1970s was considered a 'public and moral necessity'. ${ }^{18}$ This shift in approach from institutionalised care to care in the community has been attributed to many causes, including the rise of psychopharmacology, a desire to cut public expenditure, an increased emphasis on human rights and advances in social science and philosophy (see also Chapter 31 ). ${ }^{19}$ Bolstering the call for the closure of asylums was a strong service user voice, providing harrowing accounts of experiences of care and calling for patient emancipation. The Mental Patients' Union was one such group established in 1973 to demand civil and economic rights for patients, including the abolition of compulsory treatment, increased communication of treatment options and risks and the abolition of isolation as treatment. ${ }^{20} \mathrm{NAMH}$ was also centring the voices of people with mental health problems in its work, with a 1969 article in Hospital World emphasising that the charity had 'developed from a polite, reassuring body, uttering words of comfort to all those involved with mental health, to an organisation which is now firmly on the side of the patient and not at all scared of speaking its mind when the need arises'. $^{21}$

The journey from institutionalised to community care dominated NAMH annual conference agendas over this period - from 'Rehabilitation and Resettlement of Mentally Disordered People' in 1977 to 'Breakthrough: Making Community Care Work' in 1994. These events were often characterised by outpourings of frustration and anger about the poor state of services, the coercive nature of poor-quality treatment and the lack of support or recognition for people with their own experiences of mental health problems. These events acted as a convening point for many people who had struggled to find a voice.

\section{Were Communities Ready for Care in the Community?}

Deinstitutionalisation in mental health care involved three core strategies: discharging patients from hospital wards; decreasing or halting hospital admissions; and implementing alternative community-based interventions (see also Chapter 30$).^{22}$ Discharging patients and reducing admissions was largely successful, with a sharp reduction from 143,700 mental health inpatients in England in 1950 to 49,000 in 1990; the length of stays also reduced dramatically from an average stay of 863 days in 1950 to just 83 days in $1990 .^{23}$ The success of implementing community-based interventions, however, was less certain. As part of the reconfiguration of mental health services under the 1962 Hospital Plan for England and Wales, acute psychiatric inpatient services were developed at general hospitals, outpatient capacity was increased and local authorities developed community mental health teams.

The voluntary sector played a crucial role alongside local and district health authorities in managing and delivering community-based services. ${ }^{24}$ Throughout the gradual closure of 
psychiatric hospitals, it became increasingly clear that community statutory services could not meet all the needs of people who were experiencing mental distress or had learning/ intellectual disabilities. This placed a greater responsibility on the families of those with mental health problems in terms of providing care. ${ }^{25}$ It also coincided with an increase in voluntary sector organisations supporting people with mental health problems. Groups of psychiatrists, people experiencing mental health problems and other stakeholders organised themselves into voluntary sector organisations. There was an established legacy in this. Samaritans had been founded by vicar Chad Varah in 1953. The origins of the Mental Health Foundation were established as the Mental Health Research Fund in 1949. The oldest mental health charity in the UK had been Together for Mental Wellbeing, which was originally established in 1879 and had worked to find housing for female patients discharged from asylums.

Mind had been founded as the National Association for Mental Health in 1946. In 1971, NAMH launched its twenty-fifth anniversary Mind campaign, which was so successful that, in 1972, the organisation adopted Mind as its new name. The campaign sought to clarify the organisation's aims, raise funds, increase public awareness of mental health and improve hospital and community services. Under the influence of the organisation's new director, Tony Smythe, it took on a social model of care and sought to support those also receiving care in the community, as well as in hospital. As part of the 1974 strategy, Mind worked to establish more regional offices, in order to support local Mind associations across England and Wales. It also strengthened its campaign for improvements to services at a local level, as it became increasingly evident that statutory services could not meet the needs of all people experiencing mental health problems. From the 1970s through to the 1990s, concern around community care dominated the charity's public education and fundraising campaigns: 'Home from Hospital' in 1976 emphasised the housing problems faced by people discharged from hospital wards; 'A Better Life' in 1986 called for increased resources in order to develop an effective local network of care; and 'Breakthrough! Community Care' in 1994 attempted to advance a service user-centred and holistic approach to mental health care in the community. ${ }^{26}$

Local associations for mental health were newly established throughout this period in response to the needs of the community. Often formed by family members or local community leaders following the closure of an asylum, local Minds and other voluntary organisations provided hope and help in communities where people with mental health problems were often feared and stigmatised. Since this point, local Minds grew in number up to more than 200 by the start of the next century and had grown in scope too. Today, local Minds offer a variety of services to the public, including counselling and psychological therapies, housing schemes, social clubs and day centres. Arguably, voluntary and community organisations can go beyond what is offered by statutory services delivered in clinical settings; they become rooted in the communities in which they are situated, work alongside people with mental health problems to provide user-led interventions and become trusted by those people they serve. ${ }^{27}$

While support for people was an important role for the voluntary sector, it was not sufficient. As seen in the section 'A Series of Scandals: Increased Service User Voice and Pressure from the Voluntary Sector', there was a wider need for people to be regarded as equal citizens, receiving respect in society. This required mobilisation on a societal level, with campaigning, legal work and policy influencing a part of this new agenda for change. The 1970s marked a decided change in Mind's positioning in the voluntary 
sector. In 1975, the first legal officer was appointed and Mind began promoting itself as a lobbying group. In a 1981 issue of Mind Out, ${ }^{28}$ Mind's then medical advisor, Anthony Clare, noted that 'Mind has developed a lusty appetite for legal reform and the issue of patients' civil rights'. Prominent campaigners who worked at Mind included civil rights lawyer Larry Gostin, Labour MP Tessa Jowell and disability and mental health campaigner Liz Sayce. In 1979, the legal and welfare rights service became a fully fledged legal department (see also Chapter 8). Mind's subsequent campaigns again demonstrated the preoccupation with deinstitutionalisation - from the 'Home from Hospital' $1976 \mathrm{cam}$ paign, highlighting the housing problems faced by people with mental health problems, to the 1986 'A Better Life' campaign, raising public awareness of the lack of resources for the development of a local network of care. Gostin's 1975 publication with Mind, A Human Condition, is said to have largely influenced the 1982 Mental Health (Amendment) Act, including increased opportunities for tribunal review, as well as detailed regulations for consent and treatment. ${ }^{29}$ The 'Breakthrough! Community Care' campaign in 1994 demanded 'proper care in the community'. In January 1995, Tessa Jowell MP presented the Community Care Bill to the House of Commons alongside Mind, which highlighted the failures of the government to properly implement the Community Care Act, meaning that care in the community was 'far from an effective reality'.

\section{The Role of Family, Friends and Carers}

Mental health care in the community meant shared care of people with mental health problems, from both mental health professionals and family members. The Schizophrenia Fellowship (now Rethink Mental Illness) was founded in 1972, after a father, John Pringle, shared his son's experience of schizophrenia in the Times. In 1973, Rethink launched its first support groups for carers and three years later received its first government funding to expand this work. ${ }^{30}$ Then, in 1995, Rethink published its ground-breaking Silent Partners report commissioned by the Department of Health, which was the largest survey at that time of those caring for people with mental health problems. Many of the issues highlighted in that survey still resonate today. The $\mathrm{C} 4 \mathrm{C}$ (Caring for Carers) survey reported on seventyone UK respondents who were caring for a family member with a severe mental illness in $2015 .^{31} \mathrm{It}$ found that family caregivers had typically cared for their relative for sixteen years and spend approximately twenty-nine hours per week caregiving. The report also highlighted that support for these carers was lacking and they often felt unheard. Worryingly, the UK ranks the highest internationally in terms of perceived stigma felt by family caregivers in seeking professional help.

More recently, the efforts of carers, in the form of family and friends, have been better recognised in mental health service provision and research. As highlighted in a 2017 paper on carer involvement in mental health inpatient units, ${ }^{32}$ engaging carers in mental health treatment can help to improve patient symptoms and quality of life as well as reduce inpatient admissions. ${ }^{33}$ Consequently, more and more mental health policies recommend the involvement of carers in the treatment of people with mental health problems. For instance, the 2010 UK publication Recognised, Valued and Supported: Next Steps for the Carers Strategy focused on how best to support both carers and those they care for. ${ }^{34}$ The 2014 Care Act built on these intentions by enabling carers to complete a carer's assessment to obtain support from their local authority. 
Despite these positive steps, many barriers still exist that prevent carers from becoming fully involved in their family member's or friend's mental health care, with perspectives of people with mental health problems and carers still sorely lacking in services and research literature. ${ }^{35}$ Carers of people receiving mental health care in the UK have experienced difficulties in navigating these services, with communication gaps and discontinuities in treatment. In a qualitative exploration of these experiences, a carer of her son with schizophrenia expressed her frustration with repeated staff changes in services: 'as soon as I get to know one, then they've gone. It used to be very upsetting, very disruptive, because every time there was a new doctor or a new key worker or a new social worker, or whoever, you've got to start right from scratch.' Another woman caring for her husband with schizophrenia expressed the difficulties when carers have to work with mental health professionals with whom they have no established contact: 'it's an absolutely vital lifeline to have somebody that knows you, that listens to you, that responds to you, at the other end of the phone.' Voluntary organisations such as Rethink and the Carer's Trust are still fighting to support these individuals in carer roles and to ensure their voices are at the centre of conversations around mental health support in the UK.

\section{Tackling Stigma}

Stigmatising attitudes towards mental health problems have existed in various forms since before the establishment of asylums in Britain. For a long time, stigma meant that people experiencing mental health problems were kept out of sight. As segregated care moved to care in the community, the conversation shifted from concern for the welfare of those patients discharged into the community to fears of dangerousness and a desire to protect the public. The murder of Jonathan Zito ignited public fear and popular 'mad axeman' and 'psychopathic murderer' myths dominated debate around community care. ${ }^{36}$ People were keen to protect themselves and the communities in which they lived; a survey carried out in 1994 by the Department of Health showed that 22 per cent of people in the UK felt that locating mental health facilities in a residential area would downgrade the area. ${ }^{37}$ Fears of dangerousness still exist today and are perpetuated in the media. For instance, a study in 2019 of tweets about mental health generated by the UK national press revealed that 24 per cent of tweets presented mental illness as 'bad news' stories, as opposed to 'understanding' stories. ${ }^{38}$ The global director of Time to Change, Sue Baker OBE, stressed that 'we are still picking up the pieces from terrible headlines of "mad psycho killers" mid to late 90 s' $^{39}$

The voluntary sector and government increased their efforts to tackle these stigmatising attitudes towards mental health. In 1997, the Health Education Authority launched their making headlines initiative, pushing for less sensationalised portrayals of mental illness in the national press. A study at the time showed that nearly half of articles in the news media referencing mental health presented it negatively and associated mental illness with criminality and violence. ${ }^{40}$ The SHiFT anti-stigma campaign was launched to promote a disability-inclusion model of mental health and involved crossdepartmental governmental input. In more recent times, Rethink and Mind jointly launched the Time to Change campaign in 2007 to tackle stigma, which has reported a 9.6 per cent positive change in attitudes towards mental health between 2008 and 2016 . While stigmatising attitudes towards mental health still exist today, these are slowly starting to change for the better. 
These campaigns were centred around the voices of people with mental health problems. Time to Change established a community of thousands of champions, people with lived experience, who could tell their own story. ${ }^{41}$ These champions challenge stigma around mental health by sharing their experiences, talking about their mental health, forming campaigning groups and influencing the work of the Time to Change campaign. One champion, Sophie, feels that 'involving yourself in open and non-judgemental conversations regarding mental health is an absolutely crucial first step towards fighting stigma and ending discrimination', ${ }^{42}$ This work has helped to put the voices of people with mental health problems at the forefront of mental health campaigning. As one champion, Sian, puts it, 'the way society views mental health is changing. We are talking more and more, showing people that it is OK not to be OK, that it can happen to any of us. ${ }^{43}$ By the time the period 1960-2010 was coming to an end, the same voices were back on the streets campaigning for better mental health legislation.

Mind's approach to tackling stigma has long been focused on creating space for the voices of those experiencing mental health problems. For instance, the October 1974 edition of Mind Out was devoted entirely to the experiences and views of people with experience of mental health problems, and in 1987 Mind launched the service user advisory group Mindlink. ${ }^{44}$ Mind continues to ensure that lived experience is at the centre of its work, with people with mental health problems involved in strategy planning, service development as well as governance, with a commitment that at least half of Mind's board have lived experience of mental health problems.

\section{Conclusion}

The voluntary sector has been an adaptive but constant source of support for individuals with mental health problems throughout this period of dramatic transformation in mental health services between 1960 and 2010. Charities sought to assist in providing local-level support when the vast majority of care moved from hospital wards to care in the community. The voluntary sector also fought to tackle the stigmatising attitudes towards mental health that negatively impacted communities as mental health patients were discharged. Ensuring that people with lived experience of mental health problems were heard and respected has been at the core of this work. Charities, such as Mind, continue to fight against stigmatising attitudes and to develop and deliver user-led community-based interventions to support all those people in need of help.

\section{Key Summary Points}

- The move from institutionalised care to care in the community was partly caused by, and in turn further strengthened, the voices of people with mental health problems.

- Charities are in a unique position, sitting outside of statutory care and clinic-based spaces, allowing them to build reciprocal and trust-based relationships with the communities that they serve.

- Mind (then known as the National Association for Mental Health, NAMH) condemned the handling of the 1970s inquiries into psychiatric hospitals in the Observer and worked in solidarity with service user groups such as the Patients' Association calling for more independent inquiries. Mind's approach to tackling stigma has long been focused on creating space for the voices of those experiencing mental health problems. 
- Worryingly, the UK ranks the highest internationally in terms of perceived stigma felt by family caregivers in seeking professional help. The Schizophrenia Fellowship (now Rethink Mental Illness), founded in 1972 after a father, John Pringle, shared his son's experience of schizophrenia in the Times, launched its first support groups for carers and three years later received its first government funding to expand this work.

- Time to Change established a community of thousands of champions, people with lived experience, who could tell their own story. These champions challenge stigma around mental health by sharing their experiences, talking about their mental health, forming campaigning groups and influencing the work of the Time to Change campaign.

\section{Notes}

1. S. Lawton-Smith and A. McCulloch, A Brief History of Specialist Mental Health Services. London: Mental Health Foundation, 2013.

2. A. Rogers and D. Pilgrim, Mental Health Policy in Britain. London: Palgrave Macmillan, 2001.

3. J. Turner, R. Hayward, K. Angel et al., The history of mental health services in modern England: Practitioner memories and the direction of future research. Medical History (2015) 59: 599-624.

4. H. C. Merivale, My Experiences in a Lunatic Asylum: By a Sane Patient. Glasgow: Good Press, 2019.

5. F. Reid, 'His nerves gave way': Shell shock, history and the memory of the First World War in Britain. Endeavour (2014) 38: 91-100.

6. T. Loughran, Shell-shock and psychological medicine in First World War Britain. Social History of Medicine (2009) 22: 79-95.

7. Loughran, Shell-shock and psychological medicine; Reid, 'His nerves gave way'.

8. T. E. Webb, 'Dottyville': Craiglockhart War Hospital and shell-shock treatment in the First World War. Journal of the Royal Society of Medicine (2006) 99: 342-6.

9. N. Bouras, Historical and international perspectives of services. In C. Hemmings and N. Bouras, eds, Psychiatric and Behavioural Disorders in Intellectual and Developmental Disabilities, 3rd ed., 1-14. Cambridge: Cambridge University Press, 2016.

10. A. Bennett, Untold Stories. London: Faber \& Faber, 2008.

11. I. Butler, M. Drakeford and J. Campling, Scandal, Social Policy and Social Welfare. Bristol: Policy Press, 2005; C. A. Hilton, A tale of two inquiries: Sans Everything and Ely. The Political Quarterly (2019) 90: 185-93.

12. B. Robb, Sans Everything: A Case to Answer. London: Thomas Nelson, 1967.

13. C. Hilton, Whitewash and after: 'Most good is done by stealth.' In C. Hilton, Improving Psychiatric Care for Older People, 201-49. London: Palgrave Macmillan, 2017.

14. Ibid.

15. Ibid.

16. Turner, Hayward, Angel et al., The history of mental health services in modern England.

17. Enoch Powell's Water Tower Speech 1961. High Royds Hospital website (n.d.), www.highroydshospital.com /resource/enoch-powells-water-tower-speech-1961/.

18. A. Charlesworth, R. Murray, L. Bennett et al., Making Change Possible: A Transformation Fund for the NHS. London: Health Foundation and the King's Fund, 2015.

19. Lawton-Smith and McCulloch, Brief History of Specialist Mental Health Services; Turner, Hayward, Angel et al., The history of mental health services in modern England; Charlesworth, Murray, Bennett et al., Making change possible. 
20. Unknown [S.], The Mental Patients Union, 1973. libcom.org website, 21 March 2017, https://libcom.org/hi story/mental-patients-union-1973.

21. Mind, A history of Mind. Mind website (n.d.), www.mind.org.uk/about-us/what-we-do/our-mission/a-his tory-of-mind/.

22. Charlesworth, Murray, Bennett et al., Making change possible.

23. Turner, Hayward, Angel et al., The history of mental health services in modern England.

24. Charlesworth, Murray, Bennett et al., Making change possible.

25. A. J. Shah, O. Wadoo and J. Latoo, Psychological distress in carers of people with mental disorders. British Journal of Medical Practitioners (2010) 3: 18-25.

26. Mind, A history of Mind.

27. L. Weeks, Mental health charities can help people where the NHS cannot. The Guardian, 30 April 2015.

28. Cited in Shah, Wadoo and Latoo, Psychological distress in carers of people with mental disorders.

29. C. Ford, Mind the Gap: A History of Mind and the Impact of the 1960s Civil Rights Movement on Its Development. Bristol: University of Bristol, 2016.

30. Rethink, Our history. Rethink website (n.d.), www.rethink.org/aboutus/who-we-are/our-history/.

31. B. Vermeulen, H. Lauwers, N. Spruytte et al., Experiences of Family Caregivers for Persons with Severe Mental Illness: An International Exploration. Leuven: LUCAS KU Leuven/EUFAMI.

32. D. Giacco, A. Dirik, J. Kaselionyte and S. Priebe, How to make carer involvement in mental health inpatient units happen: A focus group study with patients, carers and clinicians. BMC Psychiatry (2017) 17: 1-13.

33. E.g. R. M. Norman, A. K. Malla, R. Manchanda, R. Harricharan, J. Takhar and S. Northcott, Social support and three-year symptom and admission outcomes for first episode psychosis. Schizophrenia Research (2005) 80: 227-34.

34. Department of Health, Recognised, Valued and Supported: Next Steps for the Carers Strategy. London: HMSO, 2010.

35. L. E. Rose, R. K. Mallinson and B. Walton-Moss, Barriers to family care in psychiatric settings. Journal of Nursing Scholarship (2004) 36: 39-47.

36. See the published lecture J. Laurance, Pure Madness: How Fear Drives the Mental Health System. London: Faculty of Public Health, 2002, https://www.kingsfund.org.uk/sites/default/files/puremadness.pdf.

37. Time to Change, Attitudes to Mental Illness 2013 Research Report, February 2015.

38. M. Bowen and A. Lovell, Stigma: The representation of mental health in UK newspaper Twitter feeds. Journal of Mental Health (2019): 1-7.

39. F. Morse, The Sun newspaper's '1,200 killed by mental patients' headline labelled 'irresponsible and wrong.' The Independent, 7 October 2013.

40. G. Ward, Making Headlines: Mental Health and the National Press. London: Health Education Authority, 1997.

41. Time to Change, Personal stories. Time to Change website (n.d.), www.time-to-change.org.uk/personalstories.

42. Time to Change, We can build a society that cares about people with mental health problems. Time to Change (Personal Stories 2016) website, 17 August 2016, www.time-to-change.org.uk/blog/we-can-build-societycares-about-people-mental-health-problems. This is in the public domain and not to be used for marketing/ campaign materials.

43. Time to Change, 'Self-stigma' is real and we need to talk about it. Time to Change (Personal Stories 2019) website, 2 December 2019, www.time-to-change.org.uk/blog/self-stigma-real-and-we-need-to-talk-about-it. This is in the public domain and not to be used for marketing/campaign materials.

44. Ford, Mind the Gap. 